\title{
El guerrero y el técnico. Albano Harguindeguy y su relato sobre la represión y los desaparecidos (Argentina, 1976-2012)
}

\begin{abstract}
The warrior and the technician. Albano Harguindeguy and his public word on the repression and the disappeared (Argentina, 1976-2012).
\end{abstract}

\author{
Paula Vera Canelo \\ Centro de Investigación para los Trabajadores- \\ Universidad Metropolitana para la Educación y el Trabajo- \\ CONICET, Universidad de Buenos Aires y Universidad Nacional de San Martín, Argentina \\ pvcanelo@yahoo.com
}

\section{Resumen:}

El artículo analiza la palabra pública de Albano Harguindeguy sobre la represión de la última dictadura civico-militar argentina y sobre los desaparecidos, entre 1976 y 2012. Para ello, recurre a los ejes conceptuales que Feld y Salvi (2016) proponen para abordar las declaraciones de los represores. En primer lugar, el trabajo identifica las características del relato público de Harguindeguy: qué dijo y qué no pudo dejar de decir sobre la represión y los desaparecidos. En segundo lugar, analiza el vínculo que construyó hacia ese relato, en términos de su propia responsabilidad y la de las Fuerzas Armadas: arrepentimiento, justificación, reivindicación, etc. Por último, explica cuáles fueron las principales condiciones de posibilidad de este relato: las posiciones desiguales que ocupó Harguindeguy entre 1976 y 2012, el tránsito de la dictadura a la democracia, y los vaivenes entre impunidad y justicia propios de la escena argentina de los últimos treinta y cinco años.

Palabras Clave: Harguindeguy, Represión, Desaparecidos, Ministerio del interior, Ruiz Palacios.

\section{Abstract:}

The article analyzes the public word of Albano Harguindeguy about the repression of the last Argentine civil-military dictatorship and about the disappeared, between 1976 and 2012. For this, he resorts to the conceptual axes that Feld and Salvi (2016) propose to address the repressors' declarations. First, the work identifies the characteristics of Harguindeguy's public story: what he said and what he could not stop saying about the repression and the disappeared. Secondly, it analyzes the link that he built towards that story, in terms of his own responsibility and that of the Armed Forces: repentance, justification, vindication, etc. Finally, it explains what the main conditions of possibility of this story were: the unequal positions occupied by Harguindeguy between 1976 and 2012, the transition from dictatorship to democracy, and the unsteadiness between impunity and justice typical of the Argentine scene of the last thirty-five years.

KEYWORDS: Harguindeguy, Repression, Disappeared, Ministry of the interio, Ministry of the interior, Ruiz Palacios.

\section{INTRODUCCIÓN}

Aunque fue un personaje central de la historia argentina reciente, el general Albano Harguindeguy, ministro del Interior de la última dictadura cívico-militar, no ha sido objeto de la literatura especializada. Tematizado esporádicamente por algunas investigaciones periodísticas (Cox, 2010; Robin, 2004) y/o apologéticas del terrorismo de Estado (Reato, 2016), estas se detuvieron más en la espectacularización de su palabra pública que en historizarla o analizarla en forma sistemática.

Sin embargo, la palabra pública de Harguindeguy condensa un conjunto de atributos que, creemos, la transforman en un interesante objeto de estudio.

Primero, porque Harguindeguy fue uno de los funcionarios más poderosos del autodenominado "Proceso de Reorganización Nacional”, designado entre 1976 y 1981 al frente de una de las carteras clave en la estructura gubernamental: el Ministerio del Interior (Canelo, 2014; Gené, 2014). Desde ese cargo, Harguindeguy desempeñó importantes funciones estratégicas para la dictadura, tanto represivas como políticas. Por un lado, controló gran parte de la información "legal” producida sobre el terror de Estado, 
manejó los vínculos del gobierno con las fuerzas de seguridad que actuaban en la "lucha contra la subversión" bajo control operacional militar, y gozó de un gran control territorial y poblacional. Por otro lado, sostuvo una presencia casi cotidiana en los medios de comunicación y fue uno de los principales portavoces del gobierno de Videla, mantuvo los vínculos con los partidos políticos y con los gobernadores provinciales, etc.

Segundo, porque durante el terrorismo de Estado Interior fue la cartera gubernamental (legal) más vinculada con la represión clandestina e ilegal, lo que ubicó a Harguindeguy en la intersección entre aquello sobre lo que se podía hablar, la versión "oficial" sobre la represión, y aquello que debía ser ocultado, la naturaleza clandestina y criminal de la política represiva ejecutada. ${ }^{1}$ Mostraremos en este trabajo que el estar ubicado en ese límite entre lo decible y lo que debía ser negado, lo colocó en lo que llamaremos una "posición imposible".

Tercero, porque a pesar de haber estado tan estrechamente vinculado con la represión ilegal, Harguindeguy fue uno de los funcionarios procesistas más impunes. Aunque fue señalado en numerosos testimonios sobre la represión como responsable de crímenes atroces, y aunque fue citado a declarar en diferentes causas por secuestros, detenciones ilegales, desapariciones y otros delitos, durante casi tres décadas también disfrutó de una considerable impunidad. Recién en el año 2012 fue sometido a juicio oral y público por delitos de lesa humanidad en el marco de la "Megacausa Harguindeguy"; sin embargo, falleció poco antes de conocer la sentencia.

Y último, porque como han advertido Feld y Salvi (2016), las declaraciones públicas de los represores o perpetradores del terrorismo de Estado constituyen un aspecto, si bien controvertido, sin dudas muy significativo de los procesos sociales y memoriales a través de los cuales elaboramos colectivamente nuestro pasado reciente. No se trata aquí de recuperar la palabra de Harguindeguy para poner a prueba su carácter verdadero o falso, moralmente aceptable o reprobable, sino de vincularla con sus múltiples efectos, políticos, memoriales y sociales.

En este artículo analizamos la palabra pública de Albano Harguindeguy entre los años 1976 (cuando fue designado ministro de Videla) y 2012 (momento de su fallecimiento). Si bien abordamos un extenso corpus en el que Harguindeguy habla sobre variadas temáticas, nos concentraremos en aquellas declaraciones vinculadas con la represión dictatorial y los desaparecidos.

Recurriendo a los ejes conceptuales propuestos por Feld y Salvi (2016) para analizar la palabra pública de los represores, identificamos, en primer lugar, las características del relato público de Harguindeguy sobre la represión y los desaparecidos: qué dijo y qué no pudo dejar de decir, y cuáles fueron los componentes principales de este relato (lo que llamaremos el componente "heroico" o "guerrero" y el componente "técnico").

En segundo lugar, analizamos el vínculo que construyó Harguindeguy hacia ese relato sobre la represión y los desaparecidos, en términos de su propia responsabilidad, y la de las Fuerzas Armadas: arrepentimiento, justificación, reivindicación u otros.

Por último, vinculamos lo anterior con las condiciones de posibilidad de esta palabra pública, tanto en lo referido a los momentos históricos y memoriales como a los escenarios en los que la misma tuvo lugar. Explicamos así cuáles fueron los principales efectos que sobre esta palabra pública tuvieron las posiciones desiguales que ocupó Harguindeguy entre 1976 y 2012, el tránsito de la dictadura a la democracia, y los vaivenes entre impunidad y justicia propios de la escena política argentina de los últimos treinta y cinco años.

\section{UN “SUPERMINISTRO” ENTRE LO LEGAL Y LO ILEGAL}

Albano Eduardo Harguindeguy nació en la provincia de Córdoba en el año 1927. Del arma de caballería, egresó de la promoción N. 74 del Colegio Militar de la Nación, para desarrollar una destacada carrera militar. Durante el tercer gobierno peronista (1973-1976) se desempeñó como Jefe IV (Logística) del Estado Mayor del Ejército, para ser nombrado por el general Jorge Rafael Videla, entonces Comandante en Jefe, como $2^{\circ}$ 
jefe del Cuerpo de Ejército I. Antes del golpe de Estado de marzo de 1976 se desempeñó como Jefe de la Policía Federal, lo que le otorgó una particular experiencia en el manejo de las fuerzas de seguridad y amplios vínculos personales con dicho mundo (Canelo, 2014).

Fue designado como Ministro del Interior por Videla en 1976, cargo en el que permaneció durante 5 años, y desde el que se consagró como uno de los funcionarios más poderosos y paradigmáticos del Proceso: como un verdadero "superministro". Su palabra pública sobre la represión debe ser analizada en el marco de la posición privilegiada de enunciador que ocupó durante la dictadura, y además por estar al frente de una pieza gubernamental estratégica, ubicada en la intersección entre lo legal y lo ilegal.

Considerado (hasta la creación de la Jefatura de Gabinete de ministros en 1994) como la "cartera política" del gabinete nacional, durante la dictadura Interior cumplió no sólo sus funciones tradicionales, como el control poblacional, las relaciones con los partidos políticos, los gobernadores provinciales y los medios de comunicación (Canelo, 2014; Gené, 2014), sino otras especialmente estratégicas para el Proceso.

Estas funciones "reales" de la cartera fueron reglamentadas tardíamente por la Junta Militar, en agosto de 1978, en el documento secreto "Pautas de la Junta Militar al Poder Ejecutivo Nacional (para el ejercicio de la acción de gobierno 1979/81)”. ${ }^{2}$ Allí, los Comandantes en Jefe establecían que el "Área Interior e Institucional" debía vincular estrechamente los objetivos represivos con los objetivos políticos (Junta Militar, 2014, 30/8/1978, Tomo 3, pp. 62-63). Es así que Harguindeguy debía articular nada menos que la "lucha contra la subversión" y el control de la actividad política, con la promoción del consenso de la sociedad y la conducción del diálogo con personalidades destacadas del "quehacer nacional" (el llamado "diálogo político") (Canelo, 2014).

Las funciones represivas, clandestinas y criminales, que la dictadura argentina se propuso, y que alcanzaron su mayor ferocidad precisamente durante la gestión de Harguindeguy, llevaron a modificar el organigrama, la misión y las funciones del ministerio. Esta modificación fue consagrada mediante el Decreto Secreto N. ${ }^{\circ}$ 325, firmado por Videla en 1978 (BORA, 14/2/1978, Decreto S 325/1978, p. 36).

Desde el punto de vista del organigrama, Interior pasaba a tener tres subsecretarías: de Interior, General y de Asuntos Institucionales, entre otras importantes dependencias. ${ }^{3}$ Al frente de la Subsecretaría del Interior Harguindeguy designó a uno de sus hombres de confianza, el (también cordobés) coronel (RE) José David Ruiz Palacios, un antiperonista furioso que cumplió funciones ejecutivas sobre la Policía Federal argentina, cuando dicha fuerza manejaba nueve Centros Clandestinos de Detención (Kollmann, 1991). Tras su paso por Interior, Ruiz Palacios fue designado por el presidente Roberto Viola como gobernador de facto de la provincia de Chaco (1981-1983), lo que le permitirá lanzarse a la política profesional tras la transición democrática, permaneciendo más impune aún que el propio Harguindeguy.

Los demás subsecretarios que acompañaban a Harguindeguy en Interior fueron elegidos de acuerdo con la norma de reparto tripartito del poder: el capitán de navío (RE) Ernesto R. Orbea era nombrado Subsecretario General en representación de la Armada, y el comodoro (RE) Adolfo González Albarracín, hombre de la Fuerza Aérea, fue designado en la Subsecretaría de Relaciones Institucionales.

Interior fue la cartera gubernamental (legal) más involucrada con la estructura ilegal de la represión. En el ámbito de la Subsecretaría del Interior de Ruiz Palacios funcionó el órgano estatal que vinculó el aparato represivo gubernamental y legal, con el ilegal, clandestino y predominantemente en manos de las Fuerzas Armadas y de seguridad: la Dirección General de Seguridad Interior.

El Decreto Secreto $N^{\circ} 325 / 78$ establecía que esta dirección tenía a su cargo "dirigir las actividades inherentes al poder de policía y seguridad interior que le competen al Ministerio del Interior, entendiendo en los aspectos funcionales y jurisdiccionales de la Policía Federal, Policía Territorial y Policías Provinciales”. También debía proveer "inteligencia de apoyo", y "entender en el ejercicio de la responsabilidad del Estado Nacional respecto a los derechos individuales y patrimoniales de las personas (afectados) por la lucha contra la subversión". El Departamento de Inteligencia de esta dirección debía "materializar el enlace técnico funcional con la 'comunidad Nacional de Inteligencia”, y su Departamento de Seguridad debía “entender 
en todas las tramitaciones vinculadas con la situación jurídica que impone el Estado de Sitio a las actividades de las personas" (BORA, 14/2/1978, Decreto S 325/1978, Anexo, folios 18 y 19). El relato público de Harguindeguy sobre la represión articuló dos componentes centrales. Primero, el que llamaremos relato "heroico" o "guerrero" de la "lucha contra la subversión", que reivindicaba valores militares tradicionales, como el espíritu de combate y marcial, la victoria militar, el sacrificio y la valentía personal; con este relato heroico se afirmaba un vínculo de absoluto compromiso institucional y de reivindicación incondicional. Segundo, el que llamaremos relato "técnico", típico del burócrata estatal, que enfatizaba valores racionales y procedimentales, empleado por Harguindeguy para "informar" sobre la "situación de los detenidos a disposición del PEN", y también para referirse al que denominaba el "problema de los desaparecidos"; este relato técnico sobre las víctimas de la represión (a las que nunca se les reconocía la condición de tales) permitía construir un vínculo de negación y/o desresponsabilización sobre los crímenes, meras "situaciones" que debían ser "informadas". ${ }^{4}$

El relato heroico fortalecía lo que en otros trabajos llamamos "consenso antisubversivo" (Canelo, 2008 y 2016), que suponía la adhesión incondicional de las Fuerzas Armadas a tres premisas fundamentales. Primero, que llevaban adelante una guerra total donde la única posibilidad era exterminar al enemigo. Segundo, que para ello eran necesarios métodos excepcionales, adecuados a la naturaleza del enemigo y que aseguraran el atamiento institucional a un pacto de sangre. $Y$ tercero, que estas acciones criminales eran, en realidad, actos sacrificiales de servicio hacia la sociedad argentina. Este "consenso antisubversivo" poseía una importancia fundamental: como recurso de cohesión de las Fuerzas Armadas, como criterio de legitimación ante la sociedad, y como capital político frente a la dirigencia civil. Mantener la condición de "Fuerzas Armadas victoriosas" en la guerra era primordial, no sólo para controlar la transición sino, sobre todo, para obtener la impunidad por los crímenes cometidos (Canelo, 2008 y 2016).

En 1978 Harguindeguy pronunció un discurso que sorprendió a los comentaristas de la época, y que luego fue recurrentemente citado pero no suficientemente analizado por la literatura. Este discurso muestra, con particular claridad, cómo las funciones legales/ilegales que cumplía Interior condicionaban la palabra pública del funcionario.

En el V Congreso de Jefes de Policías Nacionales y Provinciales, el ministro del Interior anunció la victoria en la "guerra contra la subversión”. Pero además habló de los riesgos derivados de la "interpenetración” de métodos y valores entre las "fuerzas legales" (Fuerzas Armadas y de seguridad), y entre ellas y la "subversión”. En forma peligrosamente explícita, admitió la existencia de aquello que por entonces no podía ser dicho: que la represión implementada contenía elementos tanto legales como ilegales.

Las organizaciones subversivas han sido desarticuladas (lo hemos logrado) con dolor y con el holocausto de nuestros queridos muertos (...) Sin embargo, este accionar produjo secuelas deformantes (...). La fuerza del Estado se transformó, en algunos casos, en violencia ejercida por grupos fuera de control. La falta de encuadramiento de esta violencia creó un ambiente propicio para el descontrol ético. (...) las fuerzas legales adecuamos muchos de nuestros procedimientos de combate a los usados por la subversión, el desprecio por la vida humana, intrínseco de la filosofía del enemigo, rozó a unos pocos, los desvalores de estos delincuentes causaron mella en alguno de nuestros hombres (...) ("De la subversión habló Harguindeguy”, 1978).

En su llamado a recomponer la legalidad (perdida), Harguindeguy admitió que la fuerza estatal se había "deformado" para adquirir la forma de "violencia de grupos fuera de control", es decir fuera de la ley; y que las "fuerzas legales" se habían visto "interpenetradas", no sólo entre sí, sino también por los métodos y los valores del enemigo:

La interpenetración de que hablamos también se produjo entre las Fuerzas Armadas, en especial el Ejército, y las fuerzas policiales, que operaron y operan en estrecha vinculación. (...) Esta falta de nitidez de las instituciones no es buena dentro de la estructura del Estado. (...) Por ello ustedes, señores jefes de las policías provinciales, deben buscar por todos los medios que las instituciones que mandan vayan retomando sus características específicas de fuerzas policiales. ("De la subversión habló Harguindeguy”, 1978). 
En la palabra pública de Harguindeguy el relato heroico de la "guerra sucia" convivió con un relato técnico. Mediante este discurso burocrático, racional y procedimental, el ministro "informaba" sobre la situación de los detenidos a disposición del Poder Ejecutivo Nacional (PEN) y también cuando, ocasionalmente, se refería a los desaparecidos. No se trataba nunca de víctimas, sino de números, estadísticas y situaciones que podían ser clasificadas, de hechos que había que "exponer racionalmente", situaciones y hechos con los que era posible mantener un vínculo de negación y/o desresponsabilización.

Este relato técnico predominó en la palabra pública de Harguindeguy en el cumplimiento de uno de sus roles más importantes, el de ser portavoz de la postura oficial del régimen militar en torno a los desaparecidos. La construcción de una postura oficial al respecto estuvo prácticamente ausente de la agenda de la Junta Militar durante los primeros años, para volverse urgente en 1979, al acercarse la visita de la Comisión Interamericana de Derechos Humanos (CIDH) de la Organización de Estados Americanos (Canelo, 2016; Franco, 2018).

En este plano el régimen se negaba a otorgar cifras exactas, dado que eso podría llevar a la necesidad de detallar circunstancias, responsables, etc. sobre la represión (Salvi, 2016); en otros términos, a decir sobre la represión. Poco antes de la llegada de la CIDH Harguindeguy se aprestó a dar algunas cifras, afirmando que los detenidos a disposición del PEN eran 1.723 (todos detenidos por "subversión"); asimismo, según el ministro había otros 1.077 en situaciones clasificables como "sin proceso abierto", "libertad vigilada", "arresto", "cese de arresto" u "opción a salir del país" ("Hay actualmente 1723 personas arrestadas...", 1979; "Habla el M del Interior...”, 1979) Finalmente, acompañado por Ruiz Palacios, el "superministro" anunciaba la sanción de leyes que contemplarían las situaciones familiares creadas por la desaparición de personas, previendo la posibilidad de declaración de fallecimiento y contemplando la situación previsional de los beneficiarios ("Habla el M del Interior...”, 1979). ${ }^{5}$

Retirada la CIDH, Harguindeguy pronunció otro histórico discurso dirigido "al Pueblo argentino" y transmitido por radio y televisión, que mostró las tensiones y los vínculos entre el relato heroico sobre la "guerra" y el relato técnico sobre las víctimas. El ministro reconocía que la Argentina había pagado "un precio" que debía mantenerse en secreto y sólo ser "confesado ante Dios"; frente a observadores externos como la CIDH debí mantenerse un relato técnico, mediante la exposición de "hechos concretos" y "verdades incontrastables y comprobadas":

\footnotetext{
Debe quedar bien claro que no nos hemos ‘confesado' ante la Comisión Interamericana de Derechos Humanos. La Argentina de hoy sólo se confiesa ante su Dios. Nos hemos limitado a exponer los hechos, dejando librado a sus integrantes el extraer las conclusiones pertinentes (...) Mentiras infames como la de los campos de concentración han quedado definitivamente sepultadas por la verdad incontrastable y comprobada (...) La República Argentina nada tiene que ocultar (...) Es plenamente consciente de la guerra que libró y del precio que pagó como consecuencia de la violencia desatada por la agresión de la delincuencia terrorista. Está racionalmente convencida de la necesidad y de la irreversibilidad de las acciones que debieron llevarse a cabo para derrotarla y aprobó el esfuerzo y sacrificio de sus Fuerzas Armadas, de Seguridad y Policiales (...) ("El Gobierno no se confesó ante la Comisión...”,1979).
}

Otra función fundamental cumplida por Harguindeguy durante la dictadura, de tipo político pero estrechamente ligada con sus funciones represivas, fue la de articular los vínculos entre el régimen militar y los partidos políticos. Así, en marzo de 1980, Harguindeguy se aprestó a conducir el llamado "diálogo político" con parte de la dirigencia civil que el régimen considerada "compatible": miembros de academias científicas, dirigentes de cámaras comerciales, miembros de colegios profesionales, directores de medios de comunicación, y dirigentes políticos (Canelo, 2014 y 2016).

Aunque el diálogo fue presentado como un "instrumento apto de consulta e información" entre la dictadura, por entonces en franco declive, y los civiles (Junta Militar, 1979), su objetivo más importante fue lograr el compromiso de estos últimos de que no revisarían "lo actuado" en la represión ilegal. Esto había sido plasmado por la Junta Militar en el documento secreto Bases Políticas, que definía las "Premisas básicas no negociables" por el gobierno de las Fuerzas Armadas: "la convalidación de todo lo actuado en la lucha 
contra la subversión e impedir todo revisionismo sobre los mismos [sic]" y el resguardo de "la estabilidad política futura de la Nación, asegurando la efectiva intervención institucionalizada de las Fuerzas Armadas en el gobierno" (Junta Militar, 2014, 5/12/1979, Tomo 3, p. 286) ${ }^{6}$

En el diálogo con los civiles Harguindeguy recurrió al relato heroico para advertir que las "Fuerzas Armadas victoriosas" sobre la "subversión" impondrían sus propias condiciones políticas sobre la transición, como la impunidad. Porque, afirmaba el ministro, "al Ejército vencedor no se lo enjuicia ni se le pide rendición de cuentas luego de la guerra” (“El diálogo”, 1980).

Sin embargo, Harguindeguy no logró concretar las "Premisas básicas". En su informe final como ministro del Interior destacó que los civiles habían presentado muchas objeciones a la "efectiva intervención institucionalizada de las Fuerzas Armadas en el gobierno" ("Harguindeguy hizo el balance de su gestión...", 1981). Aunque los civiles reconocían la condición "victoriosa” de las Fuerzas Armadas, no se había podido consensuar una "solución” sobre el tema de los desaparecidos (Canelo, 2016).

A partir de 1981, con la asunción del general Roberto Viola como presidente de la nación en reemplazo de Videla, Harguindeguy abandonó su cargo de ministro. Pero la pérdida de esta alta posición gubernamental no impidió que continuara ocupando un lugar político central (Canelo, 2016). Designado asesor de Viola, se posicionó como una autoridad pública que amenazaba hasta la del nuevo presidente y sus colaboradores: “¿Harguindeguy presidente?” se preguntaba el diario La Prensa, destacándolo como uno de los nombres más barajados para reemplazar a Viola ("El Proceso y la juventud...”,1981)

Hacia 1982, la dictadura argentina ingresó en una crisis terminal, crisis que también sería la de las propias Fuerzas Armadas, incapaces ahora de ocultar la revelación de los crímenes atroces cometidos. En abril se conocieron impactantes declaraciones de un inspector retirado de la Policía Federal, Rodolfo Peregrino Fernández, que había sido Ayudante de Harguindeguy entre abril de 1976 y enero de 1977. Ante la Comisión Argentina de Derechos Humanos (CADHU) en Madrid, el ex-inspector reveló detalles sobre la participación del Ministerio del Interior y sus funcionarios en el esquema represivo, la estructura de la represión ilegal y sus orígenes, sobre la Triple A, sobre los vínculos entre las Fuerzas Armadas, de seguridad, y organismos de inteligencia, sobre la coordinación represiva con otros países, y confirmó la existencia de lugares clandestinos de represión, donde la aplicación de torturas sobre los prisioneros (muchos de ellos desaparecidos), era una práctica habitual entre las Fuerzas Armadas y de seguridad. Según Peregrino Fernández, los perpetradores estaban atados a un "pacto de sangre consistente en la intervención personal de cada uno de ellos en la supresión de prisioneros" (Archivo Nacional de la Memoria - Fondo CONADEP (s/d): Legajo Nro. 8066)

Peregrino Fernández involucró directamente a Harguindeguy, y a varios de sus colaboradores directos, entre ellos Ruiz Palacios, en la represión ilegal. Puntualmente afirmó que Harguindeguy tuvo responsabilidad personal y directa en todo lo vinculado a la represión clandestina a través de la constitución -con personal de la Ayudantía del Ministerio del Interior al mando del sub-comisario Icely- de una brigada operativa para la realización de actos ilegales, tales como secuestros de personas; y que "de las tareas de represión ilegal tenían pleno conocimiento todo el personal de la ayudantía y los subsecretarios de Estado, Comodoro González Albarracín y el Coronel Ruiz Palacios" (Archivo Nacional de la Memoria - Fondo CONADEP (s/d): Legajo Nro. 8066, pp. 14-17) Estos funcionarios habían estado involucrados en los asesinatos y/o desapariciones de Lucía Cullen, de los curas palotinos, del obispo de La Rioja Enrique Angelelli, y de los dirigentes radicales Hipólito Solari Yrigoyen y Mario Amaya.

\section{UN “BILL DE INDEMNIDAD” PARA UN "HOMBRE COMÚN"}

¿Un bill de indemnidad? (...) No son pocos (en realidad son todos) los que se preguntan (...) por qué Harguindeguy nunca fue procesado, su nombre jamás figuró en la nómina de los condenados (...) y el fiscal Strassera tampoco se ocupó del general con quien (se dice) mantenía una secreta correspondencia cuando (...) integraba el gobierno de las juntas de comandantes 
que luego contribuyó a enviar a prisión (...) Así surgieron rumores y versiones de las más diversas especies y entre ellos, los que recordaban y recuerdan la antigua amistad que lo unió desde la juventud con el actual presidente Raúl Alfonsín ("¿Un bill de indemnidad...?”, 1987)

Los primeros años de la democracia transcurrieron en un contexto crítico, centrado en la definición de las nuevas reglas que iban a regir los vínculos entre civiles y militares. El gobierno democrático de Raúl Alfonsín (1983-1989) dio el puntapié inicial para el prolongado proceso de judicialización del accionar represivo de las Fuerzas Armadas y de seguridad durante la dictadura, por entonces centrado tras un objetivo limitado: aplicar un castigo ejemplar sobre un reducido núcleo de responsables (los Comandantes) y poder integrar a las instituciones militares al nuevo régimen (Canelo, 2013 y 2015).

Las Fuerzas Armadas ocuparon el centro de la escena. Figuras centrales del último gobierno militar, entre ellos Videla, Camps, Menéndez y Bussi, justificaban, relativizaban y/o negaban lo sucedido durante el terrorismo de Estado (Salvi, 2015). Después de todo, en estos primeros meses de la postdictadura, los desaparecidos todavía no eran vistos "ni como tan inocentes ni tan como jóvenes", aún resultaba difícil su construcción como víctimas, la "lucha antisubversiva", aplaudida pocos meses antes por gran parte de la sociedad argentina no era aún tan condenable, y las denuncias sobre la represión aún no permitían presentar una imagen clara sobre la naturaleza de los crímenes cometidos por las Fuerzas Armadas (Feld y Franco, 2015).

Sin embargo, el avance del proceso de judicialización y sus hitos fundantes, especialmente el Informe de la CONADEP (1984) y el Juicio a las Juntas (1985), modificaron progresivamente las condiciones de posibilidad de los discursos meramente negacionistas sobre el terrorismo de Estado, sus oportunidades de escucha, y sus efectos y repercusiones (Feld, 2016).

Harguindeguy se acomodó rápidamente a estos escenarios políticos y memoriales cambiantes que transitaban de la dictadura a la democracia, y de la impunidad a la judicialización. Mientras otros militares de alto rango mantenían un monótono relato heroico sobre la "guerra sucia" como el principal tema de su presencia pública, Harguindeguy buscó travestirse de "superministro" en "hombre común”, a salvo, como hombre corriente, de la condena social y, sobre todo, de la judicialización.

Transformarse en un "hombre común" era una tarea exigente. Primero, Harguindeguy debía dosificar su palabra pública. Y aunque la misma perdió sistematicidad y frecuencia, al mismo tiempo ganó interés y espectacularidad. Harguindeguy se resistía a la creciente avidez pública por sus declaraciones, reforzando su condición de hombre corriente, nada excepcional, frente a las preguntas sobre su rol en la represión: "No soy adivino, no tengo la bola de cristal, nunca dije que era mago" ("Caso Holmberg...",1983) "No soy Dios para saber todo lo que ocurría en el país durante los años que fui Ministro del Interior" ("Dura crítica del senador Menem...”, 1987); "yo no soy Jesucristo. No puedo decirle a Lázaro 'levántate y anda" ("Albano Harguindeguy a Robert Cox...”, 2016), argumentaba.

Convertirse en un "hombre común" requería también trasladar su palabra pública de los escenarios públicos a los privados. Así, Harguindeguy comenzó a construir una imagen de ex hombre público, que luego de cumplir con su "deber" de argentino y de militar se disponía a disfrutar de la recompensa de una nueva vida privada, ociosa y poco interesada en la política nacional. Uno de los pocos escenarios públicos frecuentados por Harguindeguy eran las misas de la asociación procesista FAMUS. Su nuevo gran escenario eran notas de actualidad, donde procuraba presentarse como un "paisano": "Vistiendo bombachas y botas cortas, pulóver raído, con apariencias de paisano, estuvo en esta tarde en esta localidad (Junín de los Andes), comprando diarios para enterarse de las ultimas noticias 'dado que hace días que no leo" ("Una desmentida", 1984) Sin embargo, la prensa no dejaba de destacar los atributos de alguien que "sabe matar": "se encontraba en la zona desde hace varios días cazando ciervos, su gran pasión. (...) sobre el portaequipaje de su coche, un Audi chapa B-1453.319 llevaba una hermosa cabeza de ciervo" ("Una desmentida”, 1984)

A pesar de todos los esfuerzos por mantenerse en la condición de hombre común, en mayo de 1985 Harguindeguy fue citado a declarar en el Juicio a las Juntas Militares como testigo de la fiscalía (no de la 
defensa). Su testimonio fue uno de los primeros discursos significativos pronunciados por el ex superministro en democracia.

Aunque acudía como testigo y no como acusado, en el nuevo escenario judicial la posibilidad de decir más de lo conveniente sobre la naturaleza de la represión se volvía muy peligrosa. Es así que Harguindeguy se comportó como "un testigo reticente tratando de no ser incriminado", tal como caracterizó el abogado Eduardo L. Duhalde (Duhalde, 1985) Negó la existencia de todo tipo de represión ilegal y, muy especialmente, descartó haber tenido conocimiento personal de cualquier hecho vinculado con la misma. Sus palabras eran cuidadosamente resguardadas por varios argumentos autoexculpatorios, como "no corresponde", "no intervine", "me eran ajenos", "no sé", "no recuerdo".

Pero aún en tamaño esfuerzo de negación y ocultamiento, la posición que había ocupado Harguindeguy en el límite entre la represión legal y la ilegal condicionaron inevitablemente su discurso, y lo obligaron a reconocer un conjunto de hechos que revelaban, como afirmaba Duhalde, que "no sólo sabía sobre la represión, sino que había sido parte de la misma" (Duhalde, 1985)

Interrogado por los fiscales sobre el tratamiento que el Ministerio del Interior realizaba sobre los detenidos a disposición del PEN, Harguindeguy recurrió una vez más al relato técnico y racional. Describió así los registros burocráticos de las denuncias que habían sido realizados por su cartera, aunque debió reconocer que en los mismos, como norma, no se indagaba ni sobre la fecha, ni sobre el lugar de la detención en cuestión. Y enfatizó, como forma de desresponsabilizarse de detenciones ilegales, que Interior sólo tenía conocimiento de los detenidos a disposición del PEN a partir de la existencia de un decreto (legal):

Gil Lavedra: General, usted ha afirmado que en las solicitudes de puesta a disposición del PEN no figuraba en ningún caso la fecha de detención, ¿es posible que esta información, esto es, la fecha de detención, llegara a conocimiento del Ministerio del Interior ulteriormente por alguna otra vía o conducto?

Harguindeguy: No, doctor, para nosotros figura en nuestros archivos y es receptado y es mantenido en mi memoria, la fecha de detención era la fecha que figuraba en el decreto respectivo, que era el momento que el hombre quedaba a disposición del PEN, del cual yo, como ministro del Interior, formaba parte.

GL: Es decir, que (...) en ningún caso figuraba la fecha de detención.

$\mathrm{H}$ : Doctor, yo me refiero a la generalidad, a lo mejor en una ficha, como usted me dice ningún caso, yo le puedo decir que la norma era que no figurara la fecha de detención.

GL: ¿El lugar de detención?

H: El lugar de detención tampoco (...). (Juicio a las Juntas Militares, Causa 13/84, 1985).

A pesar de las preguntas del fiscal, Harguindeguy no se refirió a los desaparecidos ("su mayor problema”, como los calificaría en el futuro), sino a los detenidos "legales” a disposición del PEN. Admitió asimismo que se mantenía informado "en general", y no en "forma puntual", y que (como "hombre común") no tenía capacidad para "recordarlo todo", por lo que no podía ser interrogado sobre casos específicos.

Gil Lavedra: General, ¿̨podría usted relatar al Tribunal cuál era la actividad del Ministerio a su cargo con relación al reclamo por personas desaparecidas?

Harguindeguy: (...) se abría una ficha, se requería información a los Comandos de las Fuerzas; cuando así se lo estimaba procedente, a la Policía Federal, a las provincias, cuando eran individuos que habitaban en el ámbito de las distintas provincias, y en base a los resultados obtenidos, se le contestaba a quien había formulado ese requerimiento; esa tarea se realizó en forma cotidiana y quedó asentada en pequeñas fichas, en las cuales nosotros le dábamos el carácter de pedido de paraderos (...).

GL: ¿Usted informaba al titular del PEN de estos pedidos de paraderos?

H: No, incluso yo no recibía todos los pedidos de paraderos, ni conocía las listas día a día, de los pedidos que se habían producido, porque imagínese que la capacidad de una persona para elaborar toda esa información (...); no obstante, sí hacia referencias a situaciones globales de cantidad de pedidos, pero no la información puntual de los distintos pedidos. (Juicio a las Juntas Militares, Causa 13/84, 1985).

Finalmente, interrogado sobre los criterios que determinaban la puesta a disposición del PEN de un individuo durante la dictadura, Harguindeguy había admitido que "no había reglas", sino "sentido común sin reglas": 
Strassera: (...) es interés de esta Fiscalía saber concretamente cuáles eran los criterios para evaluar las razones que motivaban la puesta a disposición del PEN. (...)

Harguindeguy: Bueno, tengo entendido que el artículo 23 es una facultad discrecional que le da el PEN, precisamente como una cosa de excepción, entonces no había reglas, no se dictaron normas para evaluar, de los fundamentos que cada fuerza exponía de la puesta a disposición era, vuelvo a repetir, el sentido común del propio ministro de determinar si eran valederos (Juicio a las Juntas Militares, Causa 13/84, 1985).

Involuntariamente, Harguindeguy había tenido que reconocer la doble normativa vigente sobre la represión: la legal/formal (las disposiciones de la Junta Militar y otras leyes y decretos) y la ilegal/informal/ clandestina (la cadena real de mandos de la represión).

Primero, para evitar ser responsabilizado por detenciones ilegales, y desplazar la atención hacia otros responsables indeterminados, Harguindeguy había debido aceptar en su testimonio que las personas detenidas lo eran "con anterioridad al dictado del decreto que las ponía a disposición del PEN (momento a partir del cual el ministro afirmaba tener conocimiento de le detención)”. Así, debió aceptar que Interior no había indagado ni sobre la fecha de detención, ni sobre el destino de los detenidos, es decir que no había velado ni por el cumplimiento de la ley, ni sobre la legitimidad de la detención, ni por la seguridad de los argentinos. Segundo, para evitar ser interrogado sobre casos puntuales, Harguindeguy había admitido que "se mantenía informado en general, no en forma puntual", revelando que Interior había resignado facultades "en cuanto a los traslados de cada uno de los prisioneros facilitando su ulterior destino desconocido". Y tercero, al aceptar que "no había reglas ni se dictaron normas respectivas", el exministro había revelado que "no existían criterios claros de razonabilidad jurídico-política” para colocar a los ciudadanos a disposición del PEN” (Duhalde, 1985)

Nuevamente, y como había sucedido ante las policías en 1978, al hablar sobre la represión Harguindeguy no había podido dejar de decir sobre la misma mucho más de lo que podía y convenía ser dicho por entonces, imposibilitado para escapar de los condicionamientos que le imponía a su palabra su "posición imposible". Y esto resultaba ahora mucho más riesgoso que durante la dictadura, cuando el riesgo de la judicialización ni siquiera asomaba en la desquiciada imaginación de los represores.

\section{CUANDO LA IMPUNIDAD NO ES ARREPENTIMIENTO, SINO REIVINDICACIÓN}

¿Qué quería que hiciera con los desaparecidos, que agarre una varita mágica y los haga aparecer? Yo Aladino no era. (“Camps y Harguindeguy están mejor que nunca”, 1991)

Los años ochenta confirmaron el "bill de indemnidad" del que gozaría Harguindeguy. Aunque desde 1982 había sido citado a declarar en varias causas por delitos cometidos durante la represión dictatorial y mencionado frecuentemente en los testimonios de testigos y víctimas que lo vinculaban directamente con la represión, hacia fines de la década sólo se encontraba procesado (junto a Martínez de Hoz y Videla) por el "caso Gutheim", que investigaba la privación ilegal de la libertad y la extorsión de dos empresarios textiles (Ares, 1987); "Harguindeguy declaró en el caso Gutheim”, 1987) ${ }^{7} \mathrm{Y}$ en 1988 le fue confirmada la prisión preventiva por "vejámenes" en perjuicio del gobernador riojano Carlos Menem durante la dictadura (“Harguindeguy pagó con Bonex...", 1988) ${ }^{8}$

El contexto político y memorial revertía ahora la judicialización en impunidad. Los hechos fundamentales en ese camino fueron la sanción de las Leyes de Punto Final y Obediencia Debida, y los Indultos decretados por el presidente Menem en 1989 y 1990. Gracias al Decreto de Indulto N. ${ }^{\circ} 1.002 / 89$, Harguindeguy fue sobreseído por Menem no sólo en la causa por vejámenes que él mismo le había iniciado, sino también en el “caso Gutheim” por el que cumplía prisión preventiva en una unidad militar (“El final tan temido...",1990)

Como tantos otros represores, el indulto le garantizó a Harguindeguy la impunidad. El nuevo ciclo revertía las condiciones de posibilidad de los relatos sobre la represión, entre ellos el de Harguindeguy: pero en su caso no alentó el arrepentimiento sino, por el contrario, la reivindicación de los crímenes y el más crudo cinismo. 
En diciembre de 1991 el diario Crónica reflejaba los ánimos militares del momento titulando "Camps y Harguindeguy están mejor que nunca", y reproducía una entrevista que la revista Noticias le había hecho al exministro. Allí Harguindeguy agradeció a Menem por el Indulto, reivindicó la "guerra sucia”, negó el carácter delincuencial (ilegal) de la represión, banalizó la participación policial en la misma y negó cualquier responsabilidad en los crímenes:

\begin{abstract}
Ahora resulta que yo soy el jefe de una banda de delincuentes (...). Ahora todos recuerdan que algunos comisarios de la banda de secuestradores ${ }^{9}$ participaron en la lucha contra la subversión. Y claro que participaron, si eran policías. (...) No me siento responsable de que la banda se haya organizado bajo mi gestión. ¿Sabe de qué me siento responsable yo? De que ustedes estén delante mío, que ejerzan el periodismo con total libertad y de que el país esté viviendo en libertad y en democracia. (...)

La guerra sucia fue una guerra no reconocida jurídicamente por Argentina. Nos negamos a reconocerla como tal porque cuando usted admite que tiene una guerra su adversario adquiere lo que se llama status de beligerante. En ese caso el ERP podría haber pedido un reconocimiento como beligerante. Como además tenía una zona “abierta” en Tucumán, podría haber celebrado acuerdos con otros países, recibir créditos y armamentos. No nos convenía.

Yo jamás firmé una orden de detención, porque era Ministro del Interior, y yo no conducía la lucha contra la subversión. Eso estaba bajo control operacional de las Fuerzas Armadas, tal como lo ordenó un decreto de Isabel Perón. ("Camps y Harguindeguy están mejor que nunca”, 1991)
\end{abstract}

Refiriéndose a la existencia o inexistencia de listas de desaparecidos, o de otros "archivos de la represión" que pudieran permanecer ocultos todavía, uno de los temas centrales de la agenda política y memorial de los años noventa, Harguindeguy afirmó con enorme cinismo: "se armó un archivo con legajos de todos, que fueron incinerados en la época de Bignone. ¿Qué quería que hiciera con los desaparecidos, que agarre una varita mágica y los haga aparecer? Yo Aladino no era." ("Camps y Harguindeguy están mejor que nunca”, $1991)^{10}$

Otros jefes militares, entre ellos el expresidente Bignone, aprovecharon esta modificación de las condiciones de posibilidad de los relatos sobre la represión para apuntalar la versión de la destrucción de las listas. Bignone afirmó que en la "Ley de Autoamnistía" (Ley N. 22.924 de "Pacificación Nacional", de septiembre de 1983) "se especificaba que todos los antecedentes de los beneficiados quedarían sin efecto, y por eso se incineraron los archivos de la represión"; y agregó "no creo que hubieran aportado algo nuevo, por eso dictamos la ley como un intento de hacer borrón y cuenta nueva" ("Niegan semejanzas del proceso con los jerarcas del nazismo...”, 1992)

En marzo y abril de 1995 la opinión pública fue sacudida por las "confesiones" de dos supuestos “arrepentidos”, el capitán de corbeta (RE) Adolfo Scilingo y el ex sargento del Ejército Victor Ibález, sobre su participación en la represión ilegal, abriendo un espacio amplio para la proliferación de declaraciones de distinto tipo sobre el tema. Tanto Harguindeguy como Ruiz Palacios participaron de estos debates.

El impune Ruiz Palacios, ahora diputado nacional electo por la provincia de Chaco ${ }^{11}$, afirmó "no me consta que existan ni hayan existido listas de desaparecidos; lo que sí existían eran carpetas donde se registraban los pedidos de paraderos de personas. (pero) no tengo ojos en la nuca" (Microsemanario, 1995)

A mediados de los años noventa se inició un proceso de revisión del pasado reciente que a partir de 2001 permitió el inicio de una nueva etapa de judicialización mediante la reapertura de varios juicios. Este proceso de revisión hilvanó diversos hitos, como las llamadas "confesiones" de dos participantes de la represión, el capitán de corbeta (RE) Adolfo Scilingo y el sargento Víctor Ibáñez, que amenazaron con vulnerar el pacto de sangre intramilitar y poner en riesgo el paradigma de la "reconciliación" del menemismo.

En este contexto tensionado entre la impunidad y la revisión del pasado, Harguindeguy fue entrevistado por la revista Gente. "Habla Harguindeguy”, titulaba la nota, aunque en realidad el exministro no innovó demasiado sobre su relato habitual, manteniéndose cuidadosamente dentro de lo que, por entonces, ya "no podía ser negado" (Salvi, 2016). "No existen las listas de los desaparecidos", reiteró: "Si la gente actuaba por izquierda no iban a ser tan estúpidos de dejar las pruebas" ("Habla Harguindeguy”, 1995). Y con su habitual 
cinismo al referirse a los desaparecidos, negó no sólo su total ajenidad con respecto a la represión ilegal, sino también la existencia de los CCD:

\footnotetext{
Periodista: Me voy a permitir ser un poco ingenua: ‘adónde los llevaban antes de estar bajo su responsabilidad, general? Harguindeguy: Y... en algún lugar los tenían, ¿no?

P: ¡No me va a decir ahora que, en aquel momento, no conocía la existencia de los centros clandestinosde detención! ESMA, Automotores Orletti, El Olimpo...

$\mathrm{H}$ : No, nunca supe de esos lugares. Pero, bueno, era obvio que cada fuerza guardaba en alguna parte a la gente que detenía. ("Habla Harguindeguy", 1995)
}

La única nota discordante de la entrevista fue un fuerte reclamo dirigido a los Jefes de Estado Mayor: "No son los individuos los que deben responder, sino las Fuerzas Armadas como institución. Ellas son los que deben salir en defensa de las acciones de sus hombres." "Habla Harguindeguy", 1995).

Poco después de la publicación de esta entrevista, en abril de 1995, el general Martín Balza, jefe del Ejército, pronunció la que fue considerada por la prensa como la primera "autocrítica institucional" de la fuerza de tierra, donde pidió "perdón” públicamente por los crímenes cometidos durante la dictadura. Pronto llegaron las "autocríticas" de las fuerzas restantes, primero en palabras del jefe de la Armada, almirante Enrique Molina Pico y luego del brigadier Juan Paulik, jefe de la Fuerza Aérea (Canelo, 2011 y 2012).

\section{LA PRIMERA vez de Harguindeguy}

Hasta ahora era el intocable ministro de la dictadura (...) Será el primer juicio que se desarrolle contra Harguindeguy, quien escoltó al dictador Jorge Videla en el Ministerio del Interior por cinco años, de 1976 a 1981, cuando se produjeron la mayoría de los crímenes del terrorismo de Estado. Sin embargo, pasados casi 30 años nunca compareció en el banquillo de un juicio oral. (“Desaparecidos: se viene el primer juicio a Harguindeguy...”, 2010).

Hacia fines de los años noventa y principios de los 2000 se produjeron renovados avances en el proceso de judicialización. Entre ellos, causas por robo de bebés (delito excluido de los alcances de las "leyes del perdón”), el arresto domiciliario y la aplicación de sanciones sobre varios importantes represores, el procesamiento y los pedidos de extradición por parte de cortes extranjeras, y el inicio de los "Juicios por la Verdad" (Canelo, 2011 y 2012; Feld, 2016).

A partir de 2001, los crímenes cometidos en el marco del terrorismo de Estado fueron considerados como de lesa humanidad, y por lo tanto, inamnistiables e imprescriptibles, y las Leyes de Obediencia Debida y Punto Final fueron declaradas inconstitucionales. En 2003, el Parlamento declaró "insanablemente nulas" estas "leyes del perdón”, tras lo cual la Cámara Federal de la Ciudad de Buenos Aires ordenó la reapertura de las "Causas ESMA" y "Primer Cuerpo de Ejército".

En junio de 2005, la Corte Suprema de Justicia de la Nación confirmó la medida, declarando la inconstitucionalidad de estas leyes, acelerando la presentación judicial de nuevas causas y el tratamiento de las abiertas con anterioridad (Canelo, 2016). El año 2006 constituyó una verdadera bisagra en este avance de la judicialización: las demandas de los organismos de derechos humanos fueron transformadas en política pública, y el gobierno kirchnerista desplegó un conjunto de "políticas de la memoria" (Lvovich y Bisquert, 2008), militares y de defensa consistentes (Canelo, 2016).

Los nuevos tiempos modificaron, una vez más, las condiciones de posibilidad de los relatos públicos sobre la represión, y Harguindeguy no se mantuvo al margen. En 2003, el exministro del Interior fue entrevistado por la periodista francesa Marie-Monique Robin, en el marco de la realización del documental "Escuadrones de la Muerte. La Escuela Francesa”, junto a otros represores, como Díaz Bessone y Bignone.

Con la garantía de impunidad que todavía le otorgaba el Indulto, Harguindeguy articuló un relato que, en los tempranos 2000 y frente a un interlocutor extranjero, buscaba ampliar su verosimilitud incorporando elementos de lo socialmente reconocido (Salvi, 2016) sobre la represión. 
En esta entrevista Harguindeguy se refirió (al igual que Díaz Bessone) a las enseñanzas de los instructores franceses, importadas a la Argentina a partir de la experiencia adquirida en la represión en Argelia e Indochina. Especialmente, a la estrategia de cuadriculación territorial y a los “métodos" aprendidos por las Fuerzas Armadas argentinas, que en el marco de esas enseñanzas habían secuestrado, torturado y asesinado detenidos, cometiendo "violaciones a los derechos humanos reconocidos por las Naciones Unidas" (Verbitsky, 2003).

Aunque la prensa insistió con que sus declaraciones constituían una "confesión" o un "arrepentimiento", el vínculo de reivindicación hacia el relato heroico de la "guerra sucia” permanecía intacto en Harguindeguy. No había ningún signo de arrepentimiento sobre los crímenes, sino reivindicación: "Hicimos lo que correspondía, en cumplimiento del deber militar. Empezamos bajo un gobierno constitucional y seguimos en un gobierno de facto"; "Las Fuerzas Armadas deben decirle al pueblo argentino: nosotros los libramos de ser un país marxista"; "Tengo que reconocer que cometimos errores. Si no cometiéramos errores seríamos dioses. Qué aburrido sería un país gobernado por los dioses, sin pecado, sin delito" (Verbitsky, 2003; Vales, 2012)

Incorporando elementos de lo ya socialmente reconocido e imposible de negar -la comisión de crímenes aberrantes- Harguindeguy reconocía "errores" en la conducción de la guerra, tanto estratégicos como políticos. ${ }^{12}$ Pero los errores no estaban vinculados con la naturaleza criminal de la "guerra sucia", sino con la errónea elección de una doctrina represiva que no era aplicable a la situación argentina; nuevamente, se había tratado de un problema de orden técnico.

El error cometido por los mandos procesistas había consistido en no apreciar que la doctrina francesa tenía "problemas de aplicabilidad" a la problemática de la "subversión” en la Argentina. Mientras que los franceses habían librado dos guerras coloniales, los argentinos "no enfrentamos a extranjeros, éramos todos nacionales. Eso es muy serio. (...) cada desaparecido tenía padres, hermanos, tíos, abuelos, que actuaron políticamente con un gran resentimiento, natural." (Verbitsky, 2003).

El año 2006 fue una bisagra no sólo en el contexto político y memorial, sino también en la situación judicial de Harguindeguy. En julio se confirmó su procesamiento por delitos cometidos en el marco del Plan Cóndor, junto a otros represores; en agosto, el caso fue elevado a juicio oral ("Plan Cóndor: La Cámara Federal confirmó...”, 2006; “Coordinación represiva...,” 2006). ${ }^{13}$ En septiembre la justicia declaró inconstitucionales los indultos que beneficiaban a Martínez de Hoz, Harguindeguy y Videla, que volvieron a estar procesados por el "caso Gutheim" ("La Justicia anuló los Indultos...", 2006). Y en febrero de 2008, Harguindeguy fue detenido y se le concedió prisión domiciliaria en su lujoso chalet de Los Polvorines (“Complicada situación judicial...”, 2008)

Fue en 2012 que llegó, finalmente, "la primera vez de Harguindeguy”, como tituló el diario Página/12. El exsuperministro que "pasados casi 30 años nunca compareció en el banquillo", ahora fue sometido a juicio oral y público. La llamada "Megacausa Área Paraná” o “Megacausa Harguindeguy” se inició a fines de marzo de 2012, en el Tribunal Oral Federal de Paraná, integrado por los jueces Roberto López Arango, Lilia Carnero y Noemí Marta Berros. Harguindeguy, de 83 años y cumpliendo prisión domiciliaria, fue acusado por delitos de lesa humanidad perpetrados durante la dictadura en perjuicio de 30 víctimas, de las cuales 4 permanecían desaparecidas ("La hora de Harguindeguy", 2012). También fueron acusados los exjefes de los regimientos de Ejército de Gualeguaychú, Juan Miguel Valentino, y de Concordia, Naldo Miguel Dasso, y varios exintegrantes de la delegación Concepción del Uruguay de la Policía Federal, por delitos de allanamiento ilegal, privación ilegítima de la libertad, torturas, asociación ilícita agravada y homicidio agravado por alevosía ("La hora de Harguindeguy", 2012).

Pero el banquillo continuó vacío. Argumentando que su condición física le impedía estar presente en el juicio oral, Harguindeguy siguió las sesiones por videoconferencia desde el Consejo de la Magistratura de la Nación (Varela, 2012). Desde "un sillón de ruedas y con los brazos cruzados", como caracterizó la prensa, el antaño elocuente represor se limitó a responder "con monosílabos" las preguntas del tribunal (Varela, 2012) 
Como a tantos otros represores, a Harguindeguy la muerte le llegó antes que la justicia. El ex superministro, luego trasvestido en hombre común, falleció el 29 de octubre de 2012 cumpliendo prisión domiciliaria, poco antes de conocer la sentencia en la megacausa que llevó su nombre. El 4 de abril de 2013 el T.O.F. de Paraná declaró "la extinción de la acción penal por muerte respecto de Albano Eduardo Harguindeguy" y dispuso su sobreseimiento (Tribunal Oral Federal Paraná, 2013, p. 298). ${ }^{14}$

\section{Conclusiones}

Harguindeguy le dice a Reato que 'mi problema como ministro del Interior eran los desaparecidos; era el problema más grande que tenía, después estaban las grandes obras energéticas, algunas peleítas entre provincias'.(Dandan, 2012)

En su carácter de Ministro del Interior de la última dictadura cívico-militar, Harguindeguy fue uno de los funcionarios clave en la construcción del relato público sobre la represión. Este relato articuló, en su palabra pública, dos componentes centrales. Primero, el que llamamos componente heroico sobre la "guerra sucia", que reivindicó el espíritu de combate, la victoria y el sacrificio militar. Este incluyó la idea de Fuerzas Armadas victoriosas, el principal capital político de los militares en la búsqueda de la impunidad ("al Ejército vencedor no se lo enjuicia"), y la de acto de servicio sacrificial, que consolidaban el "consenso antisubversivo" en el frente interno militar.

Segundo, un componente técnico, típico del burócrata estatal, que postulaba valores racionales y procedimentales, mediante el que Harguindeguy "informaba" sobre los detenidos a disposición del PEN y los desaparecidos, entre otras víctimas de los crímenes del terror de Estado, aun cuando les negara siempre tal condición, al igual que cualquier responsabilidad en los crímenes.

Durante la dictadura, ambos componentes perfilaron en Harguindeguy dos figuras contrastantes pero convivientes, típicas de la identidad militar: la del guerrero y la del técnico. El Ministro del Interior fue, al mismo tiempo, el feroz jefe que arengaba a las tropas militares y policiales a continuar la "lucha contra la subversión" hasta la victoria final, que ofrendaba a los argentinos la "sangre de sus mártires y caídos" y que como principal distracción prefería la de la caza mayor en lujosos safaris; y fue, simultáneamente, el helado funcionario de lentes gruesos que informaba con pretendida precisión, los datos y números de la masacre.

Estos componentes, heroico y técnico, convivieron sin demasiados cambios durante el largo camino recorrido por Harguindeguy entre su designación como ministro y su fallecimiento, aún bajo condiciones de posibilidad cambiantes, momentos memoriales fluctuantes, y escenarios diversos. Entre 1976 y 2012 las condiciones de la palabra pública de este perpetrador se modificaron decididamente, de acuerdo con las distintas (y muy desiguales) posiciones que ocupó Harguindeguy (de “superministro" a "hombre común”), y con los tránsitos de la dictadura a la democracia, y de la impunidad a la judicialización.

La palabra pública de Harguindeguy no puede ser comprendida independientemente de su posición privilegiada de enunciador, al frente de un ministerio estratégico para el gobierno militar. Las funciones específicas que cumplió Interior en el entramado represivo, en la intersección misma entre lo legal y lo ilegal, determinaron decididamente esta palabra, en un doble sentido: ampliando su alcance y escucha, pero llevándolo también, en algunos casos, a decir más de lo que podía ser dicho sobre la represión.

Harguindeguy habló siempre desde una "posición imposible", siempre determinado por ese espacio de superposición borroso y, cuatro décadas después, aún no suficientemente conocido, entre la represión legal y la ilegal, entre las carpetas y las fichas apiladas en los escritorios del Ministerio del Interior, y las picanas y las "leoneras" de los CCD.

Los condicionamientos de esta "posición imposible" se perciben con claridad en el discurso que pronunció Harguindeguy en 1978 frente a los jefes policiales, cuando al pedirles retornar a la "normalidad" no pudo evitar referirse a las "deformaciones" ("excesos") de una fuerza estatal degenerada en "violencia de grupos fuera de control”. También en su cuidado testimonio en el Juicio a las Juntas: allí, como agudamente percibió 
entonces Eduardo L. Duhalde, no pudo evitar admitir lo que aún no se había revelado sobre la represión, la existencia de la doble normativa vigente, legal/formal una e ilegal/informal/clandestina otra.

Estos condicionamientos también se revelan en otra constante de la palabra pública de Harguindeguy: la referencia al "problema de los desaparecidos" como el más importante que debió enfrentar en toda su vida. Ese "problema fundamental” que nunca logró clausurar, como nunca logró, tampoco, el resto de la sociedad argentina.

¿No fueron estos condicionamientos que la naturaleza de la represión le impuso a las palabras públicas o declaraciones de otros represores? Probablemente. Pero en Harguindeguy, el rostro más visible de un régimen gestado en el ocultamiento, el agente "legal" más involucrado en los crímenes de los agentes "ilegales", los abismos de esta "posición imposible" fueron ciertamente más profundos y más evidentes a la mirada del observador. Aquello que con mayor esfuerzo el régimen procuró ocultar, aquello que era la característica distintiva de la represión procesista (la intersección legal/ilegal), se mostró con mayor claridad en la palabra de este represor.

A diferencia de otros altos jefes militares, Harguindeguy mostró una importante versatilidad para acomodarse a los escenarios cambiantes que le presentaron los pasajes de la dictadura a la democracia, y los vaivenes entre la impunidad y la judicialización.

En democracia trató de construir una imagen de "hombre común" que lo obligó a (o le permitió) dosificar su palabra pública, replegarse hacia escenarios más privados que públicos, y mantener una supuesta ajenidad con los crímenes aberrantes que había cometido. Así, aquel superministro omnipresente y todopoderoso, que había arengado al Pueblo argentino a "confesarse sólo ante su Dios", buscaba despojarse rápida y convenientemente de cualquier excepcionalidad: "no recuerdo", "no soy el indicado" repetía en el estrado del Juicio a las Juntas; "no soy adivino", "no soy Dios", "yo Aladino no era", le reiteraba a los periodistas.

Este travestismo es más que comprensible: evidentemente, el (casi) inexplicable "bill de indemnidad" del que disfrutó Harguindeguy en democracia sólo podía ser gozado por un "hombre común”, entregado al reposo familiar en un lujoso chalet. ¿No hubiera resultado socialmente intolerable que esta obscena impunidad le hubiera sido garantizada a aquel desagradable funcionario que se burlaba de la desesperación de los familiares que reclamaban por sus seres queridos en las oficinas de Interior, o por el uniformado de rostro aguileño que le daba órdenes a los jefes de las policías argentinas, o por el superministro que bravuconeaba a los funcionarios de la CIDH?

La impunidad fue la compañera fiel de Harguindeguy, abandonándolo sólo en contadas ocasiones, cuando fue procesado o debió cumplir prisión preventiva o domiciliaria por un reducido puñado de causas: Gutheim, Menem, Cóndor, Quieto, Angelelli. Recién en 2012, casi treinta años después del fin de la dictadura, le llegó su "primera vez", y Harguindeguy fue sometido a juicio oral y público por delitos de lesa humanidad en el marco de la causa bautizada con su nombre. Sin embargo, falleció cumpliendo prisión domiciliaria, poco antes de conocer la sentencia que la sociedad argentina le adeudaba hacía tanto tiempo.

En este trabajo mostramos que esta impunidad casi vitalicia no alentó en Harguindeguy ni el reconocimiento de, ni el arrepentimiento por, sus crímenes. El "bill de indemnidad" que por algún motivo le fue otorgado, no lo llevó a decir esa "verdad" tan esperada sobre lo ocurrido, ni a ampliar la información disponible sobre los desaparecidos, ni sobre el destino de los nietos y nietas apropiados, ni sobre la estructura de la represión ilegal, entre muchas otras cuestiones que todavía son posibles. Por el contrario, su impunidad promovió su reivindicación de la "guerra sucia" y un inagotable cinismo.

¿Podrá ser considerada la palabra pública de Harguindeguy una evidencia de la imposibilidad de aquella fórmula tantas veces escuchada, que sostiene que para obtener "la verdad" basta con garantizarles impunidad a los represores? 


\section{Agradecimientos}

Este texto fue elaborado en el marco de un proyecto de investigación colectivo radicado en el Núcleo de Estudios sobre Memoria del IDES, titulado "Las declaraciones públicas de represores: narrativas y conflictos en la memoria social sobre el terrorismo de estado en la Argentina" (PICT 2013-0299), y dirigido por Claudia Feld y Valentina Salvi. Una primera versión de este artículo fue comentada en el II Seminario de Discusión "Investigaciones y debates sobre la palabra pública de los represores" (IDES, septiembre de 2018) bajo el título "La H es muda, pero habla. La palabra pública del represor Albano Harguindeguy entre 1976 y 2012", versión que será publicada en un libro colectivo. La investigación no hubiera sido posible sin la generosidad de Marcela Perelman y Patricia Panich (CELS), de Luciana Bertoia, y de Julieta Lenarduzzi (IDES). Agradezco los comentarios realizados por Darío Rubinstein y los miembros del Núcleo de Historia Reciente del IDAESUNSAM en diferentes etapas de la escritura.

\section{REFERENCIAS BIBLIOGRÁFICAS}

Canelo, P. (2008). El Proceso en su laberinto. La interna militar de Videla a Bignone. Buenos Aires: Prometeo.

Canelo, P. (2011). Consideraciones sobre la subordinación de las Fuerzas Armadas argentinas durante los años noventa. En A. Pucciarelli (Coord.), Los años de Menem. La construcción del orden neoliberal, (pp. 143-176). Buenos Aires: Siglo XXI.

Canelo, P. (2012). La responsabilidad y la convicción. Las 'autocríticas' del general Balza y su impacto en la interna militar argentina durante los años noventa. Militares e Política, 7, 100-116. Recuperado de http://www.lemp.h istoria.ufrj.br/revista/index.html

Canelo, P. (2013). ¿Qué hacer con las Fuerzas Armadas? Treinta años de 'cuestión militar' en la Argentina. Observatorio Latinoamericano, 12, 136-146. Recuperado de http://iealc.sociales.uba.ar/publicaciones/observatorio-latinoam ericano/

Canelo, P. (2014). Represión, consenso y diálogo político. El Ministerio del Interior durante la última dictadura militar argentina. Política. Revista de Ciencia Politica, 52(2), 217-239. Recuperado de https://revistapolitica.uchile.cl/ index.php/RP/article/view/36157/37924

Canelo, P. (2015). La descomposición del poder militar en la Argentina. Las Fuerzas Armadas durante las presidencias de Galtieri, Bignone y Alfonsín (1981-1987). Dossiers de Historia Política, 62. Recuperado de http://historiap olitica.com/dossiers/historizar-los-ochenta/

Canelo, P. (2016). La politica secreta de la última dictadura argentina (1976-1983). A 40 años del golpe de Estado. Buenos Aires: Edhasa.

Cox, D. (2010). Guerra sucia, secretos sucios. Buenos Aires: Sudamericana.

Feld, C. (2016). El imposible debate entre víctimas y victimarios: notas sobre las declaraciones televisivas de Miguel Etchecolatz (1997). Rubrica Contemporanea, 5(9), 77-101. Recuperado de https://historiarecienteargentina.wordpress.com/2016/07/24/rubrica-contemporanea-revista-de-la-univer sidad-autonoma-de-barcelona-vol-5-num-9/

Feld, C. y Franco, M. (2015). Democracia y derechos humanos en 1984, ¿hora cero?. En C. Feld y M. Franco (Dirs.), Democracia, hora cero. Actores, politicas y debates en los inicios de la posdictadura, (pp. 359-400). Buenos Aires, FCE.

Feld, C. y Salvi, V. (2016). Presentación. Cuando los perpetradores hablan. Dilemas y tensiones en torno a una voz controvertida. Rubrica Contemporanea, 5(9), 1-10. Recuperado de https://historiarecienteargentina.wordpress .com/2016/07/24/rubrica-contemporanea-revista-de-la-universidad-autonoma-de-barcelona-vol-5-num-9/

Franco, M. (2018). El final del silencio. Dictadura, sociedad y derechos humanos en la transición. Buenos Aires: FCE.

Gené, M. (2014). Al interior de la politica. Trayectorias, legitimidades y modos de hacer politica en el Ministerio del Interior (Argentina, 1983-2007) (Tesis de Doctorado inédita), Universidad de Buenos Aires - EHESS. 
Janowitz, M. (1967). El soldado profesional. Retrato politico y social. Buenos Aires: Editorial Bibliográfica Argentina.

Lvovich, D. y Bisquert, J. (2008). La cambiante memoria de la dictadura. Discursos públicos, movimientos sociales y legitimidad democrática. Buenos Aires: Biblioteca Nacional y UNGS.

Mignone, E. F. (1991). Derechos Humanos y Sociedad. El caso argentino. Buenos Aires: Colihue.

Mignone, E. F. y Conte Mc Donnell, A. (2006). Estrategia represiva de la dictadura militar. La doctrina del 'paralelismo global'. Buenos Aires: Colihue.

Reato, C. (2016). Disposición final. La dictadura por dentro y la confesión de Videla sobre desaparecidos. Buenos Aires: Penguin Random House Grupo Editorial Argentina.

Robin, M. (2004). Escuadrones de la muerte. La escuela francesa. Buenos Aires: Sudamericana.

Salvi, V. (2015). Guerra, subversivos y muertos. Un estudio sobre las declaraciones de militares en el primer año de democracia. En C. Feld y M. Franco (Dirs.), Democracia, hora cero. Actores, politicas y debates en los inicios de la posdictadura (pp.153-193). Buenos Aires: FCE.

Salvi, V. (2016). 'Entelequia', 'enmascaramiento' y 'disimulo. Las últimas declaraciones de Videla sobre los desaparecidos (1998-2012). Rubrica Contemporanea, 5(9), 103-122. Recuperado de https://historiarecienteargentina.wordpress.com/2016/07/24/rubrica-contemporanea-revista-de-la-univer sidad-autonoma-de-barcelona-vol-5-num-9/

\section{FuENTES}

Archivo Nacional de la Memoria - Fondo CONADEP (S/D): Declaración de Peregrino Fernández ante la Comisión Argentina de Derechos Humanos (CADHU), Legajo Nro. 8066.

Boletín Oficial de la República Argentina (2014): Decretos Secretos y Reservados. Decreto S 325/1978, Bs. As., 14/2/1978, Primera Sección - № 32.958, 1/9/2014.

Juicio a las Juntas Militares - Causa 13/84 (1985): Audiencia del 14 de mayo de 1985. Audiencia de presentación de prueba sostenida ante la Cámara Nacional de Apelaciones en lo Criminal y Correccional Federal de la Capital Federal. Buenos Aires: Memoria Abierta).

Junta Militar (2014). Actas de la Dictadura, documentos de la Junta Militar encontrados en el Edificio Cóndor. Buenos Aires: Ministerio de Defensa, 6 tomos. http://www.mindef.gov.ar/archivosAbiertos/centroDeDocumentos.ph p?documentos=edificioCondor Acceso el 1/10/2018

Junta Militar (1979). Bases Politicas de las Fuerzas Armadaspara el Proceso de Reorganización Nacional, 19 de diciembre de 1979.

Tribunal Oral Federal Paraná (2013). "I. de E. No: 1.960/10, 1.991/10y 2138/11 - "Harguindeguy, Albano Eduardo y otros s/inf. Art. 151 y otros del C. Penal", "DiazBessone, Ramón Genaro y otros s/inf. Art. 141 y otros delC. Penal" y "Valentino, Juan Miguel y otros s/ inf. Art. 141 yotros del C. Penal" Sentencia n013/13". Centro de información judicial, agencia de noticias del Poder Judicial. http://www.cij.gov.ar/lesa-humanidad.html Acceso el 1/10/2018

\section{NOTAS EN DIARIOS Y REVISTAS}

“¿Un bill de indemnidad? Harguindeguy y/o Strassera” (30/3/1987). La Prensa, Recuperado del Archivo Institucional del CELS.

“Albano Harguindeguy a Robert Cox: no soy Jesucristo. No puedo decirle a Lázaro 'levántate y anda” (27/3/2016) Perfil. Recuperado de https://www.perfil.com/noticias/politica/albano-harguindeguy-a-robert-cox-no-soy-jesu cristo-no-puedo-decirle-a-lazaro-levantate-y-anda-20160327-0080.phtml Acceso el 18/2/2019.

"Camps y Harguindeguy están mejor que nunca" (8/12/1991) Revista Noticias, cit. en Crónica, 8/12/1991. Recuperado del Archivo Institucional del CELS.

"Caso Holmberg. Careo a Harguindeguy y a Ojeda" (30/6/1983), Clarín, Recuperado del Archivo Institucional del CELS. 
"Complicada situación judicial del ex ministro del Interior de la dictadura. Detuvieron a Harguindeguy por el secuestro de dos empresarios" (20/2/2008) Clarin. Recuperado de https://www.clarin.com/edicionesanteriores/detuvieron-harguindeguy-secuestro-empresarios_0_Hk1beWAR6tl.html Acceso el 18/2/2019.

"Coordinación represiva de las dictaduras del Cono Sur. Plan Cóndor: piden iniciar el juicio oral a Videla, Bussi y Menéndez" (12/8/2006) Clarin. Recuperado de https://www.clarin.com/ediciones-anteriores/plan-condor-pi den-iniciar-juicio-oral-videla-bussi-menendez_0_rJNmwgVk0Fx.html Acceso el 18/2/2019.

"De la subversión habló Harguindeguy" (4/5/1978). La Nación. Recuperado del archivo personal de la autora.

"Desaparecidos: se viene el primer juicio a Harguindeguy" (23/10/2010) La Voz. Recuperado de https://www.lavoz. com.ar/noticias/politica/desaparecidos-se-viene-el-primer-juicio-harguindeguy Acceso el 18/2/2019

"Dura crítica del senador Menem al general Harguindeguy. 'Si no fuera Dios, como confiesa, se manejaba como si lo fuera”" (30/1/1987) La Razón. Recuperado del Archivo Institucional del CELS.

"El diálogo" (22/3/1980) Clarín. Recuperado del Archivo Institucional del CELS

"El final tan temido. Perfil de quien no quiso ser el pato de la boda." (21/12/1990) Clarín, Recuperado del Archivo Institucional del CELS.

"El Gobierno no se confesó ante la Comisión, afirmó Harguindeguy" (22/9/1979). La Prensa. Recuperado del Archivo Institucional del CELS.

“El Proceso y la juventud. ¿Harguindeguy presidente?” (25/9/1981). La Prensa. Recuperado del Archivo Institucional del CELS.

"Habla el M del Interior. La Comisión de Derechos Humanos que nos visitará tendrá amplio acceso a las cárceles y podrá hablar en privado con los detenidos" (23/8/1979). La Razón. Recuperado del Archivo Institucional del CELS.

"Habla Harguindeguy" (30/3/1995) Revista Gente. Recuperado del Archivo Institucional del CELS.

"Harguindeguy declaró en el caso Gutheim" (21/3/1987) Clarín. Recuperado del Archivo Institucional del CELS.

"Harguindeguy hizo el balance de su gestión" (26/3/1981) La Nación. Recuperado del archivo personal de la autora.

"Harguindeguy pagó con Bonex y justificó los 'abusos del poder” (23/3/1988) Página/12. Recuperado del Archivo Institucional del CELS.

"Harguindeguy, de nuevo KO. Prisión preventiva en el caso Menem" (26/7/1988) Página/12. Recuperado del Archivo Institucional del CELS.

“Harguindeguy: 3,295 taken off'siege' list”. 5018 originally, now 1723” (30/6/1979) Buenos Aires Herald. Recuperado del Archivo Institucional del CELS.

"Hay actualmente 1723 personas arrestadas a disposición del P.E” (30/6/1979) La Nación. Recuperado del Archivo Institucional del CELS.

"La hora de Harguindeguy" (21/3/2012) Página/12. Recuperado de https://www.pagina12.com.ar/diario/ultimas/s ubnotas/190128-58320-2012-03-21.html Acceso el 18/2/2019.

"La Justicia anuló los Indultos a Martínez de Hoz y Harguindeguy" (4/9/2006) Clarín. Recuperado de https://www.clarin.com/ultimo-momento/justicia-anulo-indultos-martinez-hoz-harguindeguy_0_SySGps X10Fl.html Acceso el 18/2/2019.

"Niegan semejanzas del proceso con los jerarcas del nazismo. Declaraciones de Viola y Harguindeguy" (24/2/1992) La Prensa. Recuperado del Archivo Institucional del CELS.

"Plan Cóndor: La Cámara Federal confirmó los procesamientos de Videla y otros represores" (27/7/2006) Clarín. Recuperado de https://www.clarin.com/ultimo-momento/plan-condor-camara-federal-confirmo-procesamien tos-videla-represores_0_HyI7QQE1RKx.html Acceso el 19/2/2019.

"Una desmentida" (29/3/1984) Clarín. Recuperado del Archivo Institucional del CELS.

Ares, C. (23/2/1987) Albano Harguindeguy. Por ejemplo. La Razón. Recuperado del Archivo Institucional del CELS.

Dandan, A. (29/4/2012) Una visita a los genocidas, Pagina/12. Recuperado de https://www.pagina12.com.ar/diario /elpais/1-192951-2012-04-29.html Acceso el 18/2/2019. 
Duhalde, E. L. (16/5/1985) La H es muda pero en Harguindeguy no lo es tanto. La Voz. Recuperado del Archivo Institucional del CELS.

Fahsbender, F. (21/8/2016) Exclusivo: el secuestrador de Macri 25 años después: "Yo lo voté, es un hombre admirable". Infobae. Recuperado de https://www.infobae.com/politica/2016/08/21/exclusivo-el-secuestrador-de-macri-25 -anos-despues-yo-lo-vote-es-un-hombre-admirable/ Acceso el 18/2/2019.

Kollmann, R. (21/4/1991), Cambio de guardia. Bussi, Ulloa, Ruiz Palacios, del Proceso a las urnas. Página/12. Recuperado del Archivo Institucional del CELS.

Microsemanario, Año 5, $\mathrm{N}^{\circ} 189$, semana del 25/3 al 2/4 de 1995. Recuperado del archivo personal de la autora.

Vales, L. (30/10/2012). El general que manejó la Federal y esparció el terror. Página/12. Recuperado de https://www .pagina12.com.ar/diario/elpais/1-206696-2012-10-30.html Acceso el 18/2/2019.

Varela, J. C. (22/3/2012) La primera vez de Harguindeguy, Página/12. Recuperado de https://www.pagina12.com.a r/diario/elpais/1-190155-2012-03-22.html Acceso el 18/2/2019.

Verbitsky, H. (2/9/2003). Pecados y delitos. Página/12. Recuperado de https://www.pagina12.com.ar/diario/elpais /1-24949-2003-09-02.html Acceso el 18/2/2019.

\section{Notas}

1 Esta condición característica de la represión argentina fue tempranamente identificada por Mignone y Conte Mc Donnell (2006), entre otros.

2 Las funciones formales de la cartera fueron definidas tardíamente, por la Ley de Ministerios N.o 22.450, en marzo de 1981.

3 Por ejemplo, la Caja de Retiros, Jubilaciones y Pensiones de la Policía Federal, la Policía Federal, la Municipalidad de Buenos Aires y el Territorio Nacional de Tierra del Fuego (BORA, 14/2/1978, Decreto S 325/1978, Anexo 1).

4 En ningún caso nuestro empleo de la categoría heroico implica valoración. Para diferenciar estos componentes contrastantes del relato sobre la represión, retomamos la distinción entre heroico/guerrero y técnico que reconoce Janowitz (1967) entre los dos tipos de liderazgo que conviven en las organizaciones militares modernas.

5 Estos números oficiales eran irrisorios comparados con los que registraban los organismos de derechos humanos desde 1976. En 1979 la Asamblea Permanente por los Derechos Humanos ya contaba con el primer registro sobre desaparecidos, que documentaba por lo menos 5.818 casos, de acuerdo con testimonios de familiares de desaparecidos y de algunos sobrevivientes de la represión (Mignone, 1991); la CIDH recibió asimismo 5.580 denuncias. "Harguindeguy: 3,295 taken off 'siege' list” titulaba el Buenos Aires Herald, para señalar las numerosas contradicciones que poblaban los "números" y "clasificaciones" informados por el régimen ("Harguindeguy: 3,295 taken off 'siege' list", 1979)

6 Este documento incluía unas "Bases Instrumentales para la Acción Política de uso exclusivo de Junta Militar", donde la Junta ya recomendaba la sanción de una "Ley Especial para los hechos derivados de la LCT impidiendo todo revisionismo posterior sobre los mismos": la futura "Ley de Autoamnistía" que sería sancionada en septiembre de 1983 (Junta Militar, 2014, 5/12/1979, Tomo 3, p. 293).

7 Federico y Miguel Gutheim, dueños de la algodonera Sadeco S.A., habían sido acusados por la dictadura de "subversión económica", y puestos a disposición del PEN el 5 de noviembre de 1976, por el Decreto N. 2.840 firmado por Videla, Martínez de Hoz y Harguindeguy, con el objetivo de favorecer económicamente a varias empresas multinacionales.

8 Menem había estado detenido en la localidad formoseña de Las Lomitas. Harguindeguy había admitido entonces, ante los abogados de Menem, que lo enviaba allí porque "ahora empieza el verano. Si hubiera sido invierno, estaría en Lago Argentino (...) no hace mucho lío...pero joder, jode” (“Harguindeguy, de nuevo KO...”, 1988)

9 Pocos meses antes de estas declaraciones de Harguindeguy la llamada "banda de los comisarios" había mantenido secuestrado durante 12 días a Mauricio Macri, entonces candidato a jefe de gobierno de la Ciudad de Buenos Aires e hijo de uno de los empresarios más poderosos de la Argentina. La "banda de los comisarios" era una de las mayores organizaciones de secuestradores de la historia argentina, y estaba integrada por policías de ultraderecha vinculados a tareas represivas y de inteligencia durante la dictadura; distintas versiones la vinculaban con Harguindeguy (Fahsbender, 2016)

10 Efectivamente, en octubre de 1983, el gobierno militar sancionó el Decreto N.² 2726/83, que disponía la destrucción de los documentos referidos a lo que los militares denominaban "lucha contra la subversión".

11 Poco después de que Harguindeguy fuera liberado por el Indulto, Ruiz Palacios se acercaba a obtener el acuerdo político necesario con el PJ de Resistencia, la capital chaqueña, para ser electo intendente, cargo en el que sucedería nada menos que a Deolindo Bittel, uno de los máximos líderes del PJ. Además, su partido Acción Chaqueña se consagraba en la 
política provincial obteniendo dos bancas en la Cámara de Diputados provincial, un integrante para el Colegio Electoral y concejales en las ciudades de Barranqueras y Fontana (Página/12, 17/5/1989). En abril de 1991, Ruiz Palacios se postuló para gobernador de Chaco, pero por no cumplir con el requisito mínimo de residencia, debió conformarse con una banca de diputado provincial, repudiado por los organismos de derechos humanos (Página/12, 29/10/1991 y 2/4/1993). En 1993 fue electo diputado nacional y ocupó su banca por cuatro años.

12 Videla reconocerá estos “errores” en la "conducción política de la guerra” casi una década después (Salvi, 2016).

13 El juicio oral de la "megacausa Plan Cóndor" comenzaría recién en marzo de 2013, ya fallecido Harguindeguy.

14 El tribunal condenó a reclusión perpetua a Dasso y Valentino, mientras que el ex policía federal de Concepción del Uruguay Julio César Rodríguez recibió 15 años de prisión y su compañero Francisco Crescenzo, 10 años. Hubo 3 absoluciones que beneficiaron a Santiago Kelly del Moral, ex jefe de sección en el Escuadrón de Gualeguaychú, Marcelo Alfredo Pérez, ex jefe Departamental, y el ex jefe de la División de Operaciones y Seguridad de la Policía de Gualeguaychú, Juan Carlos Mondragón. 